\title{
Drug susceptibility testing and mortality in patients treated for tuberculosis in high-burden countries: a multi-centre cohort study
}

Kathrin Zürcher ${ }^{12 *}$, Marie Ballif ${ }^{1 *}$, Lukas Fenner ${ }^{1}$, Sonia Borrell ${ }^{23}$, Peter M. Keller ${ }^{45}$, Joachim Gnokoro ${ }^{6}$, Olivier Marcy ${ }^{7}$, Marcel Yotebieng ${ }^{8}$, Lameck Diero ${ }^{9}{ }^{10}$, E. Jane Carter $^{910}$, Neesha Rockwood ${ }^{1112}$, Robert J. Wilkinson ${ }^{11} 1213$, Helen Cox ${ }^{14}$, Nicholas Ezati ${ }^{1516}$, Alash'le G. Abimiku ${ }^{1516}$, Jimena Collantes ${ }^{17}$, Anchalee Avihingsanon ${ }^{18} 19$, Kamon Kawkitinarong ${ }^{19}$, Miriam Reinhard ${ }^{23}$, Rico Hömke ${ }^{4}$, Robin Huebner ${ }^{20}$, , Sebastien Gagneux ${ }^{23 *}$, Erik C. Böttger ${ }^{45 *}$ Matthias Egger ${ }^{12 *}$, on behalf of the International Epidemiology Databases to Evaluate AIDS (leDEA)

1 Institute of Social and Preventive Medicine (ISPM), University of Bern, Bern, Switzerland (K Zürcher MSc, M Ballif PhD, L Fenner MD, Prof M Egger MD)

2 Swiss Tropical and Public Health Institute, Basel, Switzerland (K Zürcher MSc, S Borrel PhD, Miriam Reinhard, Prof S Gagneux PhD)

3 University of Basel, Basel, Switzerland

(K Zürcher MSc, S Borrel PhD, Miriam Reinhard, Prof S Gagneux PhD)

4 Institute of Medical Microbiology, University of Zurich, Zurich, Switzerland

(PM Keller MD, R Hömke, Prof EC Böttger MD)

5 Swiss National Center for Mycobacteria, Zurich, Switzerland

(PM Keller MD, R Hömke, Prof EC Böttger MD)

6 Centre de Prise en Charge de Recherche et de Formation, Yopougon, Abidjan, Côte d'Ivoire ( $J$ Gnokoro MD)

7 Bordeaux Population Health Research Center Inserm U1219, University of Bordeaux, France (O Marcy MD)

8 The Ohio State University, College of Public Health, Columbus, Ohio, USA

(Prof M Yotebieng MD)

9 Department of Medicine, Moi University School of Medicine, Eldoret, Kenya

(Prof EJ Carter MD)

10 Department of Medicine, Moi Teaching and Referral Hospital, Eldoret, Kenya

(Prof EJ Carter MD)

11 Welcome Centre for Infectious Diseases Research in Africa University of Cape Town, South Africa

(N Rockwood PhD, Prof RJ Wilkinson PhD)

12 Department of Medicine, Imperial College, London, W2 1PG UK

(N Rockwood PhD, Prof RJ Wilkinson PhD)

13 Francis Crick Institute, London, NW1 1AT UK

(Prof RJ Wilkinson PhD)

14 Division of Medical Microbiology and the Institute for Infectious Disease and Molecular Medicine, University of Cape Town, South Africa

(Prof H Cox PhD)

15 Institute of Human Virology, Abuja, Nigeria

(N Ezati MSc, Prof AG Abimiku PhD)

16 National Tuberculosis and Leprosy Training Center, Saye, Zaria, Kaduna State, Nigeria

( $N$ Ezati MSc)

17 Instituto de Medicina Tropical Alexander von Humboldt, Universidad Peruana Cayetano

Heredia, Lima, Peru

(J Collantes MSc)

18 HIV-NAT/Thai Red Cross AIDS Research Centre, Bangkok, Thailand

(A Avihingsanon MD, K Kawkitinarong MD) 
19 Tuberculosis Research Unit, Department of Medicine, Faculty of Medicine, Chulalongkorn University, Bangkok, Thailand

(K Kawkitinarong MD)

20 National Institutes of Allergy and Infectious Diseases, National Institutes of Health,

Bethesda, Maryland, USA

(R Huebner PhD)

21 Centre for Infectious Disease Epidemiology \& Research, School of Public Health \& Family Medicine, University of Cape Town, South Africa

(Prof M Egger MD)

* equal contribution

\section{Correspondence:}

Professor Matthias Egger

Institute of Social and Preventive Medicine (ISPM), University of Bern

Mittelstrasse 43, CH-3012 Bern, Switzerland

Phone: +41316313301 Fax: +41316313520

E-Mail: matthias.egger@ispm.unibe.ch

Running head: Drug resistant tuberculosis and HIV coinfection

Word count, inserts and supplemental digital content:

Abstract 287 words, main text (including research in context) 4081 words

Inserts: 5 tables, 1 figure, 50 references.

Supplemental Digital Content: 5 tables, 1 figure

\section{Sources of support}

This research was supported by the Swiss National Science Foundation (grant numbers 153442, 310030_166687 and 174281), the National Institutes of Allergy and Infectious Diseases (NIAID) under award numbers U01 AI096299, U01 Al069919, U01 Al069924, U01 Al069911, U01 Al069907, U01 Al096186, and U01 Al069923, and Swiss National Center for Mycobacteria, University of Zurich, Switzerland. 


\section{ABSTRACT}

Background: Drug resistance is a challenge for the global control of tuberculosis. We examined mortality in tuberculosis patients from high-burden countries, according to concordance or discordance of results from drug susceptibility testing (DST) done locally and in a reference laboratory.

Methods: We collected Mycobacterium tuberculosis isolates from adult patients in Côte d'Ivoire, Democratic Republic of the Congo, Kenya, Nigeria, South Africa, Peru, and Thailand, stratified by HIV status and tuberculosis drug resistance. Molecular or phenotypic drug susceptibility testing (DST) was done locally and at the Swiss tuberculosis reference laboratory. We examined mortality during treatment according to DST results and treatment adequacy in logistic regression models adjusting for sex, age, sputum microscopy and HIV status.

Findings: 634 tuberculosis patients were included; median age was 33.2 years, 239 (37.7\%) were female, 272 (42.9\%) HIV-positive and 69 (10.9\%) patients died. Based on the reference laboratory DST, 394 (62.2\%) strains were pan-susceptible, 45 (7.1\%) mono-resistant, 163 (25.7\%) multidrug-resistant (MDR-TB), and 30 (4.7\%) had preextensive or extensive drug resistance (pre-XDR/XDR-TB). Results of reference and local laboratories were discordant in 121 (19.1\%) cases. Overall, sensitivity and specificity to detect any resistance were $90.8 \%$ and $84.3 \%$, respectively. Mortality ranged from $6.0 \%(20 / 336)$ in patients with pan-susceptible tuberculosis treated according to WHO guidelines to $57.1 \%(8 / 14)$ in patients with resistant strains who were under treated. In logistic regression, compared to concordant DST results, the adjusted odds ratio of death was $7.33(95 \% \mathrm{Cl} 2.70-19.95)$ for patients with discordant results potentially leading to under treatment. 
Interpretation: Inaccurate DST by comparison to a reference standard led to under treatment of drug resistant tuberculosis and increased mortality. Rapid molecular DST of first- and second-line drugs at diagnosis is required to improve outcomes in patients with MDR-TB and pre-XDR/XDR-TB.

Funding: National Institutes of Allergy and Infectious Diseases, Swiss National Science Foundation, Swiss National Center for Mycobacteria.

Key words: Tuberculosis, drug resistance, MDR-TB, XDR-TB, mortality, treatment success, low- and middle-income countries. 


\section{RESEARCH IN CONTEXT}

\section{Evidence before this study}

Multidrug-resistant tuberculosis (MDR-TB) and extensively drug-resistant tuberculosis (XDR-TB) are serious threats to the World Health Organization's End-TB strategy, due to limited access to rapid drug resistance identification and appropriate treatment for patients with MDR-TB or XDR-TB in many high tuberculosis burden countries. We searched PubMed for systematic reviews and original research articles published in any language up to March 31, 2018. We combined terms for "tuberculosis", "drug resistance testing", and "mortality". Several individual studies and systematic reviews have documented the poor outcomes of MDR-TB and pre-XDR/XDR-TB in high-burden countries. Two Cochrane reviews evaluated the accuracy of molecular tests detecting specific mutations associated with resistance, for example the Xpert MTB/RIF, which is recommended by the World Health Organization to detect rifampicin resistance directly from sputum.

\section{Added value of this study}

To our knowledge, this is the first multi-country study assessing the accuracy of drug susceptibility testing (DST) in routine settings in high-burden countries by comparing local DST results with those from a tuberculosis reference laboratory, and assessing the impact on mortality. The study showed that the accuracy of local DST to detect any resistance in high-burden countries was moderate (sensitivity $90.8 \%$, specificity $84.3 \%$ ). Results from the reference and local laboratories were discordant in about $20 \%$ of patients. Mortality during treatment was increased almost two-fold in patients with discordant DST results compared to patients with concordant results. Mortality ranged from $6.0 \%$ in adequately treated patients with pan-susceptible strains to $53.3 \%$ in inadequately treated patients with drug-resistant strains. In multivariable analyses, associations with mortality changed little after adjustment for sex, age, sputum microscopy result and HIV status. Of note, HIV infection was not associated with mortality during tuberculosis treatment.

\section{Implications of all the available evidence}

Drug-resistant tuberculosis is difficult to diagnose and to treat, particularly in highburden settings, where resources are limited. In these settings, inaccurate DST leading to inappropriate treatment contributes to the high mortality associated with drugresistant tuberculosis. Local access to accurate and rapid DST of first- and second-line drugs is required to improve outcomes in patients with MDR-TB and pre-XDR/XDR-TB. Whole genome sequencing is the most promising approach to reach this goal, but much work remains to be done to make this approach feasible and affordable in high-burden countries. 


\section{INTRODUCTION}

Tuberculosis is a global public health concern. In 2016, an estimated 10.4 million individuals developed active tuberculosis worldwide, of whom an estimated 1.0 million (10\%) were HIV-positive ${ }^{1}$. The scale-up of antiretroviral combination therapy (ART) has substantially improved the prognosis of HIV-positive patients ${ }^{2,3}$, and reduced the incidence of tuberculosis in this population ${ }^{4,5}$. However, the risk of tuberculosis among HIV-positive patients on ART remains four times higher than among HIV-negative patients ${ }^{6}$.

The emergence of multidrug-resistant tuberculosis (MDR-TB) and extensively drug-resistant tuberculosis (XDR-TB) is another threat to the control of tuberculosis ${ }^{7-9}$. In 2016 , it was estimated that $4 \%$ of the new patients and $19 \%$ (up to $48 \%$ in Eastern Europe) of previously treated patients had MDR-TB ${ }^{1}$. Treatment of MDR-TB and XDRTB is challenging due to the longer treatment duration, adverse effects and lower efficacy of second-line drugs ${ }^{10,11}$. Strategies to prevent drug-resistant tuberculosis include monitoring of the prevalence of MDR-TB, wide-spread drug susceptibility testing (DST) and ensuring rapid initiation and completion of full courses of effective treatment regimens ${ }^{12,13}$. Culture-based phenotypic DST is considered the gold-standard, but is time and resource intensive, and too slow to influence decisions on starting treatment

14. Molecular-based resistance testing offers an alternative to culture-based DST ${ }^{15}$. Xpert MTB/RIF (Cepheid, Sunnyvale, CA, USA) detects resistance to rifampicin directly from sputum and provides results within 1.5 hours ${ }^{16}$, while line-probe assays (LPAs) from sputum detect resistance to isoniazid, rifampicin, ethambutol, fluoroquinolones, or second-line injectable drugs (amikacin, capreomycin, or kanamycin) and provide results within 1-2 days ${ }^{15}$. 
We compared the results of resistance testing performed locally in ART and tuberculosis programmes in high tuberculosis burden countries to those from gold standard phenotypic DST performed in the Swiss reference laboratory, and examined mortality in HIV-positive and HIV-negative tuberculosis patients with concordant and discordant test results. 


\section{METHODS}

This multi-centric cohort study is part of a larger research project on the evolution of drug-resistant Mycobacterium tuberculosis (M. tuberculosis) in the context of HIV coinfection within the International Epidemiology Databases to Evaluate AIDS (IeDEA), a global network of ART programs (see www.iedea.org) ${ }^{17,18}$. Isolates and clinical data were collected from tuberculosis patients in seven high-burden countries in subSaharan Africa, Asia and Latin America. The sample size was calculated so that the study had adequate power to detect differences in the prevalence of drug resistance between HIV-positive and HIV-negative patients.

\section{Patient recruitment and data collection}

We included adult patients aged 16 years or older who were treated for active pulmonary tuberculosis in Côte d'Ivoire, Democratic Republic of the Congo (DRC), Kenya, Nigeria, South Africa, Peru, and Thailand. All seven countries are defined by the World Health Organization (WHO) as high tuberculosis burden countries, and DRC, Kenya, Nigeria South Africa and Thailand are also high MDR-TB burden and high HIV/tuberculosis burden countries ${ }^{19}$.

HIV-positive tuberculosis patients were recruited prospectively from ART clinics participating in leDEA, HIV-negative patients from tuberculosis clinics serving the same population. In South Africa, patients included came from well-documented strain collections held at the University of Cape Town. Sites were asked to contribute pulmonary pre-treatment $M$. tuberculosis isolates from 25 or more patients within each of the four strata defined by HIV status (positive or negative) and drug resistance (MDR or pan-susceptible), for a total of 100 patients per site. Supplemental Table S1 summarizes the characteristics of participating sites. Patient characteristics were entered online in 
French or English at baseline, using the Research Electronic Data Capture (REDCap) tool ${ }^{20}$, including site, type of TB patient as defined by WHO, age, sex, HIV status, CD4 cell count at start of tuberculosis treatment (if HIV positive), sputum smear microscopy result and risk factors for tuberculosis. Treatment regimens were updated and outcomes entered during regular follow-up visits.

\section{Outcomes}

Treatment outcomes were defined according to WHO as cured, treatment completed, treatment failure, death, lost to follow-up, transferred to other clinics, ongoing treatment at the time of evaluation or unknown treatment outcome ${ }^{21}$. "Treatment success" included cured patients and patients who completed treatment ${ }^{21}$. The main outcome for this study was mortality during tuberculosis treatment. Outcome data received up to March 31 , 2018 were included in analyses.

\section{Drug susceptibility testing}

DST was performed locally using liquid or solid cultures or molecular methods: Xpert MTB/RIF or LPAs, such as Genotype MTBDRplus or MTBDRs/ tests (Hain Lifesciences, Germany). The reference laboratory of the Swiss National Center for Mycobacteria, Zurich, Switzerland performed DST using the Mycobacteria Growth Indicator Tube liquid medium system (MGIT, Becton Dickinson, USA) with the following drug concentrations: $0.1 \mathrm{mg} / \mathrm{L}$ for isoniazid, $1.0 \mathrm{mg} / \mathrm{L}$ for rifampicin, $100.0 \mathrm{mg} / \mathrm{L}$ for pyrazinamide, $5.0 \mathrm{mg} / \mathrm{L}$ for ethambutol, $1.0 \mathrm{mg} / \mathrm{L}$ for amikacin and $0.25 \mathrm{mg} / \mathrm{L}$ for moxifloxacin, in line with the critical concentrations recently published by $\mathrm{WHO}^{22}$.

WHO defines mono-resistance as resistance to one first-line anti-tuberculosis drug (isoniazid, rifampicin, pyrazinamide, or ethambutol); MDR as resistance to isoniazid and rifampicin; pre-XDR as MDR with additional resistance to any fluoroquinolone or one of 
the second-line injectable drugs (amikacin, capreomycin, or kanamycin); XDR as MDR with additional resistances to any fluoroquinolone and at least one of the second-line injectable drugs ${ }^{21}$. The category "other" drug resistance included any other combination. We defined "pan-susceptible" tuberculosis as no resistance against the six drugs tested at the reference laboratory and any resistance as resistance against at least one of the tested drugs. First-line regimens (standard treatment) included first-line anti-tuberculosis drugs (isoniazid, rifampicin, pyrazinamide, and ethambutol) and second-line regimens included a combination of first-line and second-line drugs ${ }^{21,23}$.

\section{Exposure definition and data analysis}

We calculated test accuracy statistics for the diagnosis of any drug resistance. We further classified comparisons between the phenotypic and molecular DST results obtained in the local laboratories and the reference laboratory as follow: concordant results, discordance potentially leading to under treatment, discordance potentially leading to over treatment, and other discordant results. We defined drug regimens received by patients as compatible with the WHO guidelines in place during the study period, as under treatment or as over treatment, based on the reference DST results. First-line regimens for pan-susceptible tuberculosis, first or second line-regimens prescribed to isoniazid mono-resistant patients, second line-regimens prescribed to rifampicin mono-resistant patients, MDR-TB and pre-XDR/XDR-TB patients were classified as in accordance with WHO guidelines. Under treatment included first-line regimens given to rifampicin mono-resistant patients, MDR-TB and pre-XDR/XDR-TB patients, and over treatment second-line regimens given to pan-susceptible tuberculosis patients. Supplemental Table S2 shows the classification of regimens.

We used descriptive statistics to describe patient characteristics by levels of drug resistance based on DST performed at the reference laboratory and by HIV status. We 
examined determinants of mortality in multivariate logistic regression models. Patients with unknown or missing treatment outcome, ongoing treatment, missing treatment regimen, missing sputum microscopy and "other" drug-resistant tuberculosis were excluded from logistic regression analyses. Logistic models were adjusted for age, sex, sputum microscopy result and HIV status. We stratified models by study site by including an indicator variable for all sites except South Africa (the reference group). We calculated the population attributable fraction of mortality due to discordant DST results based on the adjusted model as described by Greenland and Drescher ${ }^{24}$.

Other variables, for example smoking history, diabetes, substance abuse and contact to other tuberculosis patients worsened the fit of the model. For HIV-positive individuals, models were additionally adjusted for CD4 cell count at tuberculosis treatment start. All analyses were done using STATA version 15 (Stata Corporation, College Station, Texas, USA).

\section{Ethical statement}

Local institutional review boards or ethics committees approved the study at all participating sites. Informed consent was obtained where requested per local regulations. The study was also approved by the Cantonal Ethics Committee in Bern, Switzerland.

\section{Role of the funding source}

The sponsors of the study had no role in study design, data collection, data analysis, data interpretation, or writing of the report. The corresponding author had full access to all the data in the study and had final responsibility for the decision to submit for publication. 


\section{RESULTS}

We obtained M. tuberculosis isolates from 871 patients diagnosed between 2013 and 2016. We excluded 237 patients from analyses of the accuracy of DST, mainly because isolates were contaminated or not viable, and a further 61 patients from analyses of mortality, mainly because treatment was ongoing or outcomes unknown at the time of closing the database (supplementary Figure S1). Excluded patients were similar in terms of age, sex, HIV status, site of tuberculosis, but had lower CD4 counts and were more likely to be patients with recurrent tuberculosis and treatment after failure or

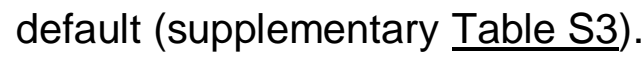

\section{Characteristics of patients and isolates}

The median age of the 634 included TB patients was 33.2 years (interquartile range [IQR] 26.9-42.5 years); 239 (37.7\%) were female. The reference laboratory identified 394 (62.1\%) pan-susceptible M. tuberculosis strains, 45 (7.1\%) mono-resistant strains, $163(25.7 \%)$ MDR strains, 30 (4.7\%) pre-XDR/XDR strains, and 2 (0.3\%) strains with other drug resistance profiles (Table 1). Among the 163 patients with MDR-TB, 85 (52.1\%) had resistance to rifampicin and isoniazid only, while the remaining patients were additionally resistant to pyrazinamide and/or ethambutol. Among the 24 patients with pre-XDR-TB, resistance to moxifloxacin $(n=15)$ was more frequent than resistance to amikacin ( $n=9$; Table 2$)$. Patients with resistant strains were more likely to receive second-line tuberculosis treatment, and to experience unfavourable treatment outcomes than patients with pan-susceptible strains (Table 1).

A total of $272(42.9 \%)$ tuberculosis patients were HIV-positive, with a median


cells $/ \mu \mathrm{l})$. Among them, 175 (64.3\%) were either on ART at the start of tuberculosis treatment or initiated ART within 3 months; the ART status of the remaining patients 
was unknown. Compared to HIV-negative individuals, HIV-positive patients were more likely to be female, more likely to have both pulmonary and extrapulmonary disease, and more likely to be patients with recurrent tuberculosis (supplemental Table S4). HIVpositive patients were also more likely to have a negative sputum smear microscopy result and more likely to have a pan-susceptible $M$. tuberculosis infection than HIVnegative patients.

\section{Drug susceptibility testing and treatments}

Local laboratories used the Xpert MTB/RIF system, culture, LPAs, or a combination of these methods to diagnose drug-resistant infections and inform treatment regimens (Table 3, supplemental $\underline{\text { Table S2}}$ ). Among the 27 isolates assessed by a combination of tests, Xpert MTB/RIF and LPA were used in 17 (63.0\%) isolates, Xpert MTB/RIF and culture in 8 (29.6\%), culture and LPA in one, and Xpert MTB/RIF, culture and LPA in another isolate.

Comparing local with reference laboratory results for any resistance, there were 218 true and 62 false positives and 332 true and 22 false negatives, for an overall sensitivity and specificity of $90.8 \%(95 \% \mathrm{Cl} 87.2-94.5)$ and $84.3 \%(80.7-87.9)$, respectively. Sensitivities and specificities were 79.5\% (68.4-88.0) and $97.1 \%$ (93.499.1) for Xpert MTB/RIF, 93.1\% (84.5-97.7) and 71.6\% (63.4-78.9) for culture, 100\% (71.5-100) and $25.0 \%(0.63-80.6)$ for LPA and $98.8 \%$ (93.4-99.9) and $27.8 \%(9.7-$ $53.5 \%)$ for combinations of tests. Considering four categories of drug resistance (rifampicin mono-resistance, isoniazid mono-resistance, MDR, pre-XDR/XDR), results from the reference laboratory and local laboratories were concordant for 513 of 634 (80.9\%) and discordant for 121 of 634 (19.1\%) patients. The proportions with concordant test results were $88.2 \%$ (216 of 245 ), $72.3 \%$ (154 of 213 ), $73.3 \%$ (11 of 15 ) 
and $73.0 \%$ (73 of 100 ) for Xpert MTB/RIF, culture, LPA, or a combination of tests, respectively $(\mathrm{P}<0.001)$.

There were 23 of 634 (3.6\%) discrepancies potentially leading to under treatment, 67 of $634(10.6 \%)$ discordant results potentially leading to over treatment, and 31 of $634(4.9 \%)$ other discordances (Table 3, supplementary Table S2). When analysing the treatments received, they were compatible with WHO guidelines in 491 of 507 (96.8\%) patients with concordant DST results compared to 94 of 121 patients (77.7\%) with discordant results $(\mathrm{P}<0.001)$.

\section{Mortality}

After excluding 61 of $634(9.6 \%)$ patients with unknown treatment outcomes, missing data or "other" drug resistance (supplementary Figure S1), mortality ranged from 5.6\% (17 of 302) among patients with pan-susceptible strains and concordant DST results to $44.4 \%$ (8 of 18) among patients with pre-XDR/XDR tuberculosis and discordant DST results (Table 4). It ranged from $9.8 \%$ (6 of 61 ) in patients with discordant results potentially leading to over treatment to $40.9 \%$ (9 of 22) in in patients with discordant results potentially leading to under treatment (Figure 1 , Table 5). Mortality ranged from $6.4 \%$ (23 of 359 ) in patients with pan-susceptible strains to $34.5 \%$ (10 of 29 ) in patients with pre-XDR/XDR tuberculosis. Mortality was higher in patients with isoniazid monoresistant strains ( 7 of $23,30.4 \%)$ than in patients with rifampicin mono-resistant strains (2 of $14,14.3 \%)$ but the difference was not statistically significant $(P=0.38$, Table 4) and the two categories were combined in further analyses. Finally, mortality ranged from $6.0 \%$ (20 of 336 ) in patients with pan-susceptible tuberculosis treated according to WHO guidelines to $57.1 \%$ (8 of 14$)$ in patients with resistant strains who were under

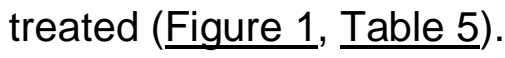


In multivariable logistic models adjusted for sex, age, sputum microscopy result and HIV status, discordant DST results continued to be associated with increased mortality compared to concordant DST results ( $\underline{\text { Table } 5)}$. Compared to concordant DST results, the adjusted odds ratio (aOR) of death was $7.33(95 \% \mathrm{Cl} 2.70-19.95)$ for patients with discordant results potentially leading to under treatment. The population attributable fraction associated with any type of discordance obtained from the logistic model was $15.15 \%(95 \% \mathrm{Cl} 2 \cdot 08-26 \%)$.

Drug resistance was associated with higher mortality compared to pansusceptible tuberculosis. The aOR was 5.06 (95\% Cl 2.74-9.35) for any type of drug resistance, and 15.19 (95\% 5.54-42.36) for pre-XDR/XDR (Table 5). Finally, compared to patients treated according to $\mathrm{WHO}$ guidelines with pan-susceptible strains, the aOR for death was $4.66(95 \% \mathrm{Cl} 2.38-9.14)$ for adequately treated patients with resistant strains and 19.32 (95\% Cl 5.59-66.73) for patients with resistant strains receiving inadequate regimens (Table 5$)$. Of note, patients with pan-susceptible tuberculosis who were over treated also had an increased risk of death: the aOR compared to patients with pan-susceptible tuberculosis treated according to WHO guidelines was 3.31 (0.8213.45, $P=0.10)$. Sex, positive sputum smear microscopy and HIV status were not associated with the odds of death. The results from univariable models were similar to the aOR from multivariable models (Table S5). When restricting the analysis to HIVpositive patients, mortality was higher among patients with CD4 cell counts $<50$ cells/ $\mu \mathrm{L}$ : the aOR was $6.89(95 \% \mathrm{Cl} 1.57-30.26)$ compared to patients with higher CD4 counts at tuberculosis treatment start. 


\section{DISCUSSION}

This study of patients treated for drug-resistant or drug-susceptible tuberculosis in seven high tuberculosis burden countries showed that the accuracy of DST testing in routine care was moderate, with discordant results from local DST compared to phenotypic DST in a reference laboratory in about 20 percent of patients. Discordant results led to inadequate treatment and contributed to the excess mortality associated with drug-resistant tuberculosis. As expected, mortality was highest in patients with preXDR/XDR tuberculosis and higher in patients who were under treated. Interestingly, patients with pan-susceptible tuberculosis who were over treated also had higher mortality, although the difference failed to reach conventional levels of statistical significance. It is possible that over treated patients had worse adherence and were at higher risk of adverse drug effects. To our knowledge, this is the first study to assess the accuracy of DST in real world, routine settings and to examine the impact of inaccurate results on mortality. Our findings support the recent call for a precision medicine approach to the treatment of drug-resistant tuberculosis, guided by detailed molecular DST done locally, to replace the standardised, empirical combination regimens used in many high tuberculosis burden low- and middle-income countries ${ }^{25}$.

At present, WHO recommends that "Xpert MTB/RIF should be used as the initial diagnostic test in individuals suspected of having MDR-TB or HIV-associated tuberculosis" ${ }^{26}$, based on a Cochrane review of test accuracy studies in adults with suspected rifampicin-resistance or MDR-TB ${ }^{27}$. In line with this recommendation, Xpert MTB/RIF was the most commonly used test in our study sites. The Cochrane review reported a pooled sensitivity of $95 \%$, based on 17 studies and 555 patients with rifampicin-resistant strains ${ }^{27}$. The pooled specificity was $98 \%$. We examined accuracy of DST strategies at the level of the local laboratories in high-burden countries, in 
routine care settings, rather than by evaluating a single test. Our estimates of sensitivity and specificity, for the detection of any drug resistance, were lower overall $(90.8 \%$ and 84.3\%, respectively), and lower for Xpert MTB/RIF (79.5\% and $97.1 \%)$ and for culture $(93.1 \%$ and $71.6 \%)$, indicating that DST is less accurate in routine settings than in test accuracy studies ${ }^{27}$.

There are concerns both about false-negative and false-positive Xpert MTB/RIF test results, and a policy of confirmatory testing has been introduced in South Africa and Brazil ${ }^{28,29}$. The discordant DST results that potentially led to under treatment of drugresistant tuberculosis (false negative for resistance) were mainly based on locally performed cultures, Xpert MTB/RIF tests, or a combination of the two. Of note, the recently developed Xpert MTB/RIF Ultra assay has been shown to improve detection of rifampicin resistance ${ }^{30}$. Culture-based tests dominated discordance that potentially led to over treatment, while Xpert MTB/RIF dominated in the category of discordance with unclear clinical significance. We acknowledge that some discordance could be explained by mixed infections, heteroresistance, or minority resistant populations ${ }^{31,32}$.

LPAs were rarely used in our study, possibly because they have been widely replaced by Xpert MTB/RIF, which is easier to use and provides results in a shorter time. In addition, LPA suffer from suboptimal accuracy for isoniazid resistance, and WHO recommends that culture-based DST for isoniazid should still be used, particularly in patients with suspected MDR-TB where the LPA result does not detect isoniazid resistance ${ }^{33}$. In one case, the local laboratory detected resistance to ethambutol but this could not be confirmed in the reference laboratory: DST is challenging for ethambutol and less reproducible ${ }^{34}$.

Data on treatment outcomes in drug-resistant tuberculosis are scarce, particularly for sub-Saharan Africa. A recent systematic review of treatment outcomes in MDR-TB 
included data on mortality among adults from seven studies from sub-Saharan Africa, six from South Africa and one from Lesotho ${ }^{35}$. In these studies, mortality during tuberculosis treatment ranged from $12.4 \%$ in patients with MDR-TB treated in a referral hospital in the Western Cape, South Africa ${ }^{36}$, to $45.8 \%$ in a study of XDR-TB patients from three South African provinces ${ }^{37}$. Our results extend these data to other countries in the region, and add further data for Peru and Thailand.

Our study confirms the poor outcome in patients with isoniazid mono-resistant tuberculosis who are treated with first-line regimens (as recommended by WHO during the study period ${ }^{38}$ ), in line with a study from Durban, South Africa ${ }^{39}$ and a recent systemic review and meta-analysis ${ }^{40}$. Mortality in mono-resistant tuberculosis patients was higher than in MDR-TB patients, especially in isoniazid mono-resistant tuberculosis. This might be due to the treatment of almost all isoniazid mono-resistant tuberculosis patients with first-line regimens, whereas most MDR-TB patients received second-line treatment. Of note, $\mathrm{WHO}$ recently updated its guidelines recommending the inclusion of fluoroquinolones in the treatment of isoniazid mono-resistant tuberculosis ${ }^{41}$. Chance is another explanation: there were only few patients with mono-resistant tuberculosis and the analysis of mortality, the confidence intervals of the odds ratios for mono-resistant and MDR tuberculosis overlapped widely (Table 5).

In patients co-infected by HIV, the treatment of drug-resistant tuberculosis is challenging for several reasons, including the poorer absorption of drugs ${ }^{42}$, the risk of the immune reconstitution inflammatory syndrome (IRIS) ${ }^{43}$, or interactions between antiretroviral and second-line tuberculosis drugs ${ }^{44-46}$. In contrast to previous studies from South Africa, which reported higher mortality at end of treatment in HIV-positive patients with MDR-TB compared to HIV-negative MDR-TB patients ${ }^{36,47}$, we found no association with HIV infection, although confidence intervals were wide. The median 
CD4 cell count of HIV-positive patients was considerably higher in our study (192 cells $/ \mu \mathrm{L}$ ) than in the South African studies ${ }^{36,47}$, which may explain the discrepant results. A study from Lesotho ${ }^{48}$ also found little evidence for a difference in mortality between HIV-positive patients (median CD4 cell count 185 cells/ $\mu \mathrm{L}$ ) and HIV-negative patients. Finally, for patients with XDR-TB, treatment outcomes have been uniformly poor in previous studies, irrespective of HIV status ${ }^{37}$.

Our study has several limitations. We sampled eligible patients within strata defined by drug resistance and HIV infection, and therefore could not estimate the incidence or prevalence of drug-resistant tuberculosis in HIV-positive or HIV-negative patients. In previous studies, HIV infection has not been consistently associated with drug resistance ${ }^{28}$, but it is clear that in regions with a high-burden of HIV, the majority of patients with MDR-TB will be co-infected with $\mathrm{HIV}^{28}$. Although we initially exceeded the planned sample size, about a quarter of patients had to be excluded from analyses of drug susceptibility, mainly due to lack of growth or contamination of cultures, and about a third was excluded from the analysis of mortality outcomes, mainly because vital status was unknown at database closure. The reference laboratory tested resistance against six drugs, and we will have missed resistance against other drugs used, for example kanamycin, ethionamide or levofloxacin. Further, the presence of different subpopulations of $M$. tuberculosis in isolates tested at the local sites vs reference laboratory might have introduced variability in phenotypic or molecular DST testing ${ }^{49}$.

In conclusion, our study shows that the accuracy of DST testing in routine care in high-burden countries was limited and that inaccurate results led to inadequate treatment and contributed to the excess mortality associated with drug-resistant tuberculosis. Our results support the notion that access to rapid molecular DST of firstand second-line drugs at treatment initiation is required to improve outcomes in patients 
with MDR-TB and pre-XDR/XDR-TB ${ }^{28}$. Whole genome sequencing is the most promising approach to reach this goal, but much work remains to be done to make this approach feasible and affordable in low- and middle-income countries ${ }^{28}$. In particular, direct testing of sputum samples should become routine to circumvent lengthy mycobacterial cultures ${ }^{40}$. A standardised approach for the interpretation of drug resistance conferring mutations has recently been developed ${ }^{50}$. In the meantime, the capacity for the phenotypic and molecular DST testing recommended by WHO should be increased to ensure the most adequate treatment of drug-resistant tuberculosis in these settings.

\section{CONTRIBUTORS}

$K Z, M B$ and ME wrote the first draft of the paper, which was reviewed by all authors and revised based on the comments received by co-authors. MB co-ordinated data and strain collection across study sites. ECB and PMK supervised DST at the Swiss National Center for Mycobacteria, which were performed by RH. HC, JG, OM, MY, LD, EJC, NR, RJW, NE, AGA, JC, AA, and KK supervised DST at the local laboratory and the collection of clinical data. ME and KZ performed statistical analyses. All authors approved the final version of the manuscript.

\section{ACKNOWLEDGEMENTS}

We thank all sites who participated in this survey and the patients whose data were used in this study. We are grateful to the Tuberculosis Working Group of leDEA for helpful discussions, and to four reviewers for thoughtful comments. We also would like to thank all regional data centers, who contributed to the coordination of the study. RJW is supported by the Francis Crick Institute (10218), which is funded by the Wellcome 
Trust, Cancer Research UK, and Research Councils UK. He also receives support from the Wellcome Trust $(104803,203135)$. HC is supported by a Wellcome Trust fellowship and reports grants from UK Medical Research Council and the National Research Foundation of South Africa. SG is supported by the Swiss National Science Foundation (310030_166687, IZRJZ3_164171, IZLSZ3_170834 and CRSII5_177163 to SG), the European Research Council (309540-EVODRTB to SG) and SystemsX.ch. ME is supported by by special project funding (Grant No. 174281) from the Swiss National Science Foundation. KK was supported by the National Research University Program, Office of the Higher Education Commission, Bangkok, Thailand, and is no financial supported from Tuberculosis Research Unit, Chulalongkorn University, Thailand, during the conduct of the study.

\section{CONFLICTS OF INTEREST}

AA has received honoraria fees from Jensen-Cilag, Gilead and Bristol-Myers Squibb. All other authors have no conflicts of interest to declare. 


\section{REFERENCES}

1 World Health Organization. Global Tuberculosis Report 2017. Geneva, 2017 DOI:WHO/HTM/TB/2017.23.

2 Egger M, Hirschel B, Francioli $\mathrm{P}$, et al. Impact of new antiretroviral combination therapies in HIV infected patients in Switzerland: prospective multicentre study. BMJ 1997; 315: 1194-9.

3 May M, Boulle A, Phiri S, et al. Prognosis of patients with HIV-1 infection starting antiretroviral therapy in sub-Saharan Africa: a collaborative analysis of scale-up programmes. Lancet 2010; 376: 449-57.

4 Antiretroviral Therapy in Low-Income Countries Collaboration of the International epidemiological Databases to Evaluate AIDS (leDEA), ART Cohort Collaboration, Brinkhof MWG, et al. Tuberculosis after Initiation of Antiretroviral Therapy in LowIncome and High-Income Countries. Clin Infect Dis 2007; 45: 1518-21. Lawn SD, Wood R, De Cock KM, Kranzer K, Lewis JJ, Churchyard GJ. Antiretrovirals and isoniazid preventive therapy in the prevention of HIVassociated tuberculosis in settings with limited health-care resources. Lancet Infect Dis 2010; 10: 489-98.

6 Gupta A, Wood R, Kaplan R, Bekker LG, Lawn SD. Tuberculosis incidence rates during 8 years of follow-up of an antiretroviral treatment cohort in South Africa: comparison with rates in the community. PLoS One 2012; 7: e34156.

$7 \quad$ Mariandyshev A, Eliseev P. Drug-resistant tuberculosis threatens WHO's End-TB strategy. Lancet Infect Dis 2017; 17: 674-5.

8 Gandhi NR, Moll A, Sturm AW, et al. Extensively drug-resistant tuberculosis as a cause of death in patients co-infected with tuberculosis and HIV in a rural area of South Africa. Lancet 2006; 368: 1575-80.

9 Klopper M, Warren RM, Hayes C, et al. Emergence and spread of extensively and totally drug-resistant tuberculosis, South Africa. Emerg Infect Dis 2013; 19: 44955.

10 Lange C, Abubakar I, Alffenaar JW, et al. Management of patients with multidrugresistant/extensively drug-resistant tuberculosis in Europe: a TBNET consensus statement. Eur Respir J 2014; 44: 23-63.

11 Horsburgh Jr. CR, Barry CE, Lange C. Treatment of Tuberculosis. N Engl J Med 2015; 373: 2149-60.

12 Wright A, Zignol M, Van Deun A, et al. Epidemiology of antituberculosis drug resistance 2002-07: an updated analysis of the Global Project on AntiTuberculosis Drug Resistance Surveillance. Lancet 2009; 373: 1861-73.

13 Falzon D, Jaramillo E, Schunemann $\mathrm{HJ}$, et al. WHO guidelines for the programmatic management of drug-resistant tuberculosis: 2011 update. Eur Respir J 2011; 38: 516-28.

14 Köser CU, Bryant JM, Becq J, et al. Whole-genome sequencing for rapid susceptibility testing of M. tuberculosis. N Engl J Med 2013; 369: 290-2.

15 Schon T, Miotto P, Koser CU, Viveiros M, Bottger E, Cambau E. Mycobacterium tuberculosis drug-resistance testing: challenges, recent developments and perspectives. Clin Microbiol Infect 2017; 23: 154-60.

16 Boehme CC, Nabeta P, Hillemann D, et al. Rapid molecular detection of tuberculosis and rifampin resistance. NEJM 2010; 363.

DOI:10.1056/NEJMoa0907847.

17 Egger M, Ekouevi DKD, Williams C, et al. Cohort Profile: the international epidemiological databases to evaluate AIDS (leDEA) in sub-Saharan Africa. Int $J$ 
Epidemiol 2012; 41: 1256-1264. PMCID: PMC3465765.

18 McGowan CC, Cahn P, Gotuzzo E, et al. Cohort Profile: Caribbean, Central and

South America Network for HIV research (CCASAnet) collaboration within the International Epidemiologic Databases to Evaluate AIDS (leDEA) programme. Int J Epidemiol 2007; 36: 969-76.

19 World Health Organization. Use of high burden country lists for TB by WHO in the post-2015 era. Geneva, 2015

DOI:http://www.who.int/tb/publications/global_report/high_tb_burdencountrylists20 16-2020.pdf.

20 Harris PA, Taylor R, Thielke R, Payne J, Gonzalez N, Conde JG. Research electronic data capture (REDCap)-A metadata-driven methodology and workflow process for providing translational research informatics support. J Biomed Inform 2009; 42: 377-81.

21 World Health Organization. Companion handbook to the WHO guidelines for the programmatic management of drug-resistant tuberculosis. Geneva, 2014 DOI:WHO/HTM/TB/2014.11.

22 Technical Report on critical concentrations for drug susceptibility testing of medicines used in the treatment of drug-resistant tuberculosis. Geneva, 2018 http://www.who.int/tb/publications/2018/WHO_technical_report_concentrations_T B_drug_susceptibility/en/.

23 World Health Organization. Definitions and reporting framework for tuberculosis 2013 revision (updated December 2014). 2014.

24 Greenland S, Drescher K. Maximum likelihood estimation of the attributable fraction from logistic models. Biometrics 1993; 49: 865-72.

25 Cox H, Hughes J, Black J, Nicol MP. Precision medicine for drug-resistant tuberculosis in high-burden countries: is individualised treatment desirable and feasible? Lancet Infect Dis 2018; 3099: 11-6.

26 World Health Organization. Policy Statement: Automated Real-Time Nucleic Acid Amplification Technology for Rapid and Simultaneous Detection of Tuberculosis and Rifampicin Res... - PubMed - NCBI. Geneva, 2011 https://www.ncbi.nlm.nih.gov/pubmed/26158191 (accessed Jan 6, 2018).

27 Steingart KR, Schiller I, Horne DJ, Pai M, Boehme CC, Dendukuri N. Xpert® MTB/RIF assay for pulmonary tuberculosis and rifampicin resistance in adults. Cochrane database Syst Rev 2014; 1: CD009593.

28 Dheda K, Gumbo T, Maartens G, et al. The epidemiology, pathogenesis, transmission, diagnosis, and management of multidrug-resistant, extensively drug-resistant, and incurable tuberculosis. Lancet Respir Med 2017. DOI:10.1016/s2213-2600(17)30079-6.

29 Sanker P, Ambika AP, Santhosh VT, et al. Are WHO approved nucleic acid amplification tests causing large-scale 'false identification' of rifampicin-resistant tuberculosis?: Programmatic experience from south india. Int J Mycobacteriology 2017; 6: 21-6.

30 Chakravorty S, Simmons AM, Rowneki M, et al. The new Xpert MTB/RIF ultra: Improving detection of Mycobacterium tuberculosis and resistance to Rifampin in an assay suitable for point-of-care testing. MBio 2017; 8.

DOI:10.1128/mBio.00812-17.

31 Rinder H, Mieskes KT, Löscher T. Heteroresistance in Mycobacterium tuberculosis. Int J Tuberc Lung Dis 2001; 5: 339-45.

32 Cohen T, van Helden PD, Wilson D, et al. Mixed-strain mycobacterium tuberculosis infections and the implications for tuberculosis treatment and control. Clin Microbiol Rev 2012; 25: 708-19. 
33 World Health Organization. Policy update. The use of molecular line probe assays for the detection of resistance to isoniazid and rifampicin. Geneva, 2016 http://www.who.int/tb/publications/molecular-test-resistance/en/.

34 Kim SJ. Drug-susceptibility testing in tuberculosis: Methods and reliability of results. Eur Respir J 2005; 25: 564-9.

35 Bastos ML, Lan Z, Menzies D. An updated systematic review and meta-analysis for treatment of multidrug-resistant tuberculosis. Eur. Respir. J. 2017; 49: 1600803.

36 Mugabo P, Adewumi AO, Theron D, Burger A, Van ZL. Do HIV infection and antiretroviral therapy influence multidrug-resistant tuberculosis treatment outcomes? African J Pharm Pharmacol 2015; 9: 875-80.

37 Pietersen E, Ignatius E, Streicher EM, et al. Long-term outcomes of patients with extensively drug-resistant tuberculosis in South Africa: A cohort study. Lancet 2014; 383: 1230-9.

38 Seung K, Satti H. Management of MDR-TB : A field guide. A companion document to Guidelines for the programmatic management of drug-resistant tuberculosis. 2010.

39 van der Heijden YF, Karim F, Mufamadi G, et al. Isoniazid-monoresistant tuberculosis is associated with poor treatment outcomes in Durban, South Africa. Int J Tuberc Lung Dis 2017; 21: 670-6.

40 Gegia M, Winters N, Benedetti A, van Soolingen D, Menzies D. Treatment of isoniazid-resistant tuberculosis with first-line drugs: a systematic review and metaanalysis. Lancet Infect Dis 2017; 17: 223-34.

41 World Health Organization. WHO treatment guidelines for isoniazid-resistant tuberculosis. Supplement to the WHO treatment guidelines for drug-resistant tuberculosis. Geneva, 2018 http://apps.who.int/iris/bitstream/handle/10665/260494/9789241550079eng.pdf?sequence $=1$.

42 Gurumurthy P, Ramachandran G, Hemanth Kumar AK, et al. Malabsorption of rifampin and isoniazid in HIV-infected patients with and without tuberculosis. Clin Infect Dis 2004; 38: 280-3.

43 Muller M, Wandel S, Colebunders R, et al. Immune reconstitution inflammatory syndrome in patients starting antiretroviral therapy for HIV infection: a systematic review and meta-analysis. Lancet Infect Dis 2010; 10: 251-61.

44 Burman WJ, Gallicano K, Peloquin C. Therapeutic implications of drug interactions in the treatment of human immunodeficiency virus-related tuberculosis. Clin Infect Dis 1999; 28: 419-29; quiz 430.

45 Gopalan N, Chandrasekaran P, Swaminathan S, Tripathy S. Current trends and intricacies in the management of HIV-associated pulmonary tuberculosis. AIDS Res. Ther. 2016; 13: 34.

46 Meintjes G. Management of drug-resistant TB in patients with HIV co-infection. $J$ Int AIDS Soc 2014; 17: 19508.

47 Gandhi NR, Andrews JR, Brust JCM, et al. Risk factors for mortality among MDRand XDR-TB patients in a high HIV prevalence setting. Int $J$ Tuberc Lung Dis 2012; 16: 90-7.

48 Seung KJ, Omatayo DB, Keshavjee S, Furin JJ, Farmer PE, Satti H. Early outcomes of MDR-TB treatment in a high HIV-prevalence setting in southern Africa. PLoS One 2009; 4: 2-8.

49 Merker M, Kohl TA, Roetzer A, et al. Whole genome sequencing reveals complex evolution patterns of multidrug-resistant Mycobacterium tuberculosis Beijing strains in patients. PLoS One 2013; 8: e82551. 
50 Miotto P, Tessema B, Tagliani E, et al. A standardised method for interpreting the association between mutations and phenotypic drug resistance in Mycobacterium tuberculosis. Eur Respir J 2017; 50. DOI:10.1183/13993003.01354-2017. 
TABLES AND FIGURES 
Table 1: Patient characteristics by phenotypic drug resistance profiles obtained at the Swiss National Center for Mycobacteria.

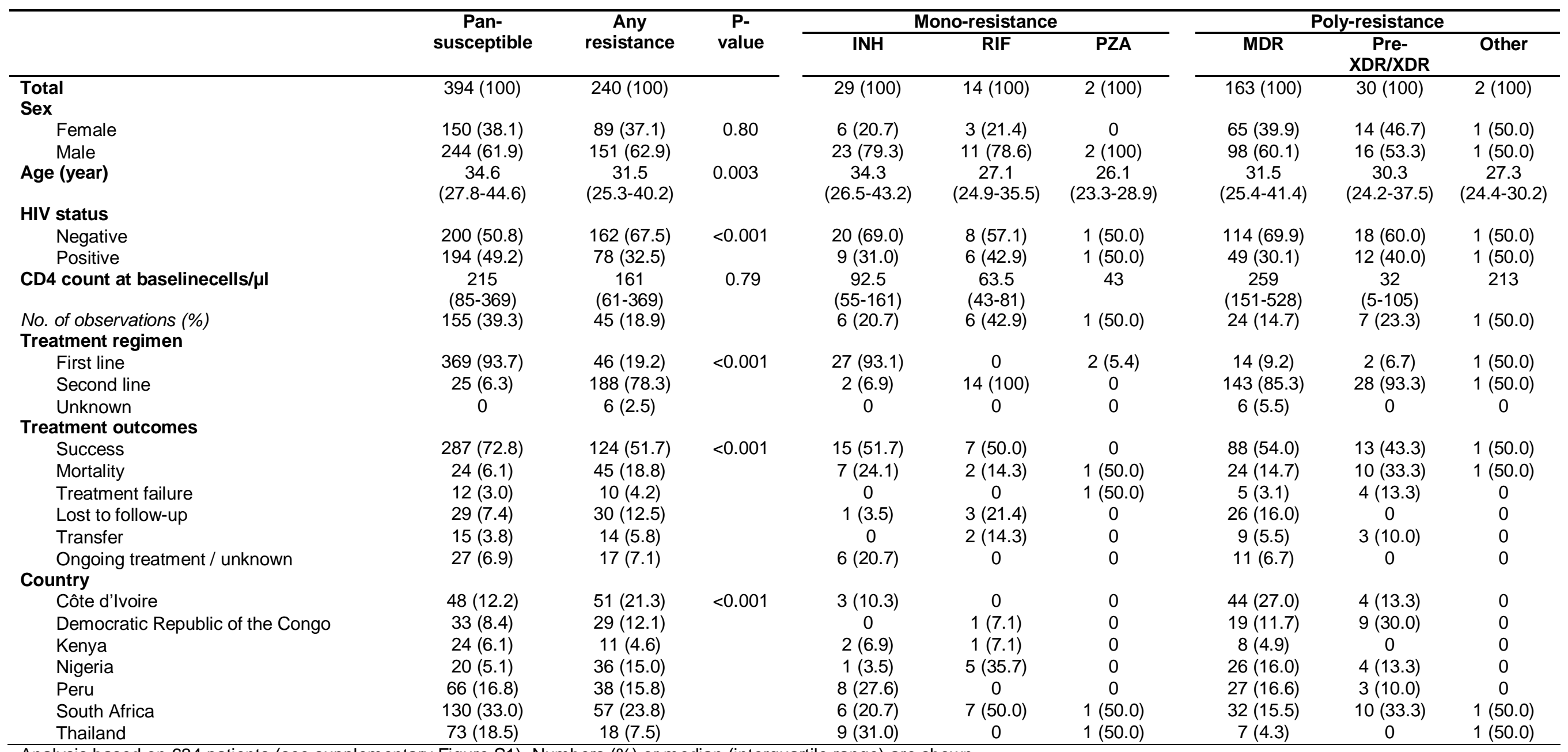

Analysis based on 634 patients (see supplementary Figure S1). Numbers (\%) or median (interquartile range) are shown.

$\mathrm{INH}$, isoniazid; MDR, multidrug resistant; PZA, pyrazinamide; RIF, rifampicin; XDR, extensively drug resistant. 
Table 2: Drug resistance profiles identified at the Swiss National Center for Mycobacteria.

\begin{tabular}{lcc}
\hline \multicolumn{2}{c}{ Resistance profiles } & No. of patients \\
& $(\mathrm{n}=634)$ \\
\hline Pan-susceptible & $394(62.2 \%)$ \\
Mono-resistance & $45(7.1 \%)$ \\
& INH mono-resistance & 29 \\
& RIF mono-resistance & 14 \\
& PZA mono-resistance & 2 \\
MDR & & $163(25.7 \%)$ \\
& INH+RIF & 85 \\
& INH+RIF+EMB & 11 \\
& INH+RIF+PZA & 47 \\
INH+RIF+EMB+PZA & 20 \\
Pre-XDR & $24(3.2 \%)$ \\
INH+RIF +MOX+EMB+PZA & 8 \\
INH+RIF +MOX+EMB & 1 \\
INH+RIF +MOX+PZA & 4 \\
INH+RIF +MOX & 2 \\
INH+RIF +AMK+PZA+EMB & 4 \\
INH+RIF +AMK+PZA & 4 \\
INH+RIF +AMK & 1 \\
XDR & INH+RIF +AMK+MOX+EMB & $6(0.8 \%)$ \\
Other & INH+RIF +AMK+MOX+PZA & 3 \\
INH+RIF +AMK+MOX & 2 \\
INH+MOX & 1 \\
INH+PZA & $2(0.3 \%)$ \\
\hline
\end{tabular}

Analysis based on 634 patients (see supplementary Figure S1).

AMK, amikacin; EMB, ethambutol; INH, isoniazid; MDR, multidrug resistant; MOX, moxifloxacin; PZA, pyrazinamide; RIF, rifampicin; XDR, extensively drug resistant. 
Table 3: Concordance and discordance of drug susceptibility results obtained from reference and local laboratories.

\begin{tabular}{|c|c|c|c|c|c|c|c|}
\hline \multirow[b]{2}{*}{$\begin{array}{l}\text { Concordance/ } \\
\text { discordance of } \\
\text { DST results }\end{array}$} & \multicolumn{2}{|c|}{ DST results by laboratory } & \multirow{2}{*}{$\begin{array}{r}\text { Total } \\
(n=634)\end{array}$} & \multicolumn{4}{|c|}{ Test used at local laboratories } \\
\hline & $\begin{array}{l}\text { Reference laboratory } \\
\text { (phenotypic) }\end{array}$ & Local laboratories & & $\begin{array}{l}\text { Xpert } \\
\text { MTB/RIF }^{a}\end{array}$ & Culture & LPA & $\begin{array}{l}\text { Combination } \\
\text { of tests }\end{array}$ \\
\hline \multirow{6}{*}{ Concordance } & Pan-susceptible & Pan-susceptible & $332(64.7)$ & $167(77.3)$ & $101(65.6)$ & $1(9.1)$ & $5(6.8)$ \\
\hline & RIF mono-resistance & RIF mono-resistance & $8(1.6)$ & 0 & 0 & 0 & $7(9.6)$ \\
\hline & INH mono-resistance & INH mono-resistance & $8(1.6)$ & 0 & $8(5.2)$ & 0 & 0 \\
\hline & MDR & MDR & $153(29.8)$ & $49(22.7)$ & $44(28.6)$ & $8(72.7)$ & $52(71.2)$ \\
\hline & Pre-XDR and XDR & Pre-XDR and XDR & $12(2.3)$ & 0 & $1(0.6)$ & $2(18.2)$ & $9(12.3)$ \\
\hline & Total & & $513(100)$ & $216(100)$ & $154(100)$ & $11(100)$ & $73(100)$ \\
\hline \multirow{3}{*}{$\begin{array}{l}\text { Discordance } \\
\text { potentially } \\
\text { leading to under } \\
\text { treatment }\end{array}$} & MDR & Pan-susceptible & $5(21.7)$ & $2(25.0)$ & $2(22.2)$ & 0 & $1(16.7)$ \\
\hline & Pre-XDR and XDR & MDR & $18(78.3)$ & $6(75.0)$ & $7(77.8)$ & 0 & 5 (83.3) \\
\hline & Total & & $23(100)$ & $8(100)$ & $9(100)$ & 0 & $6(100)$ \\
\hline \multirow{6}{*}{$\begin{array}{l}\text { Discordance } \\
\text { potentially } \\
\text { leading to over } \\
\text { treatment }\end{array}$} & Pan-susceptible & RIF mono-resistance & $14(20.9)$ & 0 & 0 & $3(100)$ & $10(71.4)$ \\
\hline & Pan-susceptible & MDR & $14(20.9)$ & $3(60.0)$ & 8 (18.2) & 0 & $3(21.4)$ \\
\hline & Pan-susceptible & Other mono-resistance ${ }^{b}$ & $33(49.3)$ & $2(40.0)$ & $31(70.5)$ & 0 & 0 \\
\hline & Other mono-resistance ${ }^{c}$ & MDR & $5(7.5)$ & 0 & $5(11.4)$ & 0 & 0 \\
\hline & MDR & Pre-XDR or XDR & $1(1.5)$ & 0 & 0 & 0 & $1(7.1)$ \\
\hline & Total & & $67(100)$ & $5(100)$ & $44(100)$ & $3(100)$ & $14(100)$ \\
\hline \multirow{8}{*}{$\begin{array}{l}\text { Other } \\
\text { discordance }\end{array}$} & Pan-susceptible & EMB, SM & $1(3.2)$ & 0 & $1(16.7)$ & 0 & 0 \\
\hline & RIF mono-resistance & MDR & $7(22.6)$ & $2(12.5)$ & 0 & 0 & $5(28.6)$ \\
\hline & Other mono-resistance ${ }^{d}$ & Pan-susceptible & $17(54.8)$ & $13(81.3)$ & $3(50.0)$ & 0 & 0 \\
\hline & INH, MOX & Mono-resistance & $1(3.2)$ & 0 & $1(16.7)$ & 0 & 0 \\
\hline & IHN, PZA & MDR & $1(3.2)$ & 0 & $1(16.7)$ & 0 & 0 \\
\hline & MDR & RIF mono-resistance & $3(9.7)$ & 0 & 0 & $1(100)$ & $2(71.4)$ \\
\hline & MDR & EMB, SM & $1(3.2)$ & $1(6.2)$ & 0 & 0 & 0 \\
\hline & Total & & $31(100$ & $16(100)$ & $6(100)$ & $1(100)$ & $7(100)$ \\
\hline
\end{tabular}

Analysis based on 634 patients (see supplementary Figure S1). Number of patients (\%) are shown.


drug resistant.

In some patients the test used to diagnose drug-resistant infection at the local laboratories was unknown. Therefore, numbers do not always add up to the row totals.

${ }^{a}$ RIF resistance diagnosed with Xpert MTB/RIF was classified as MDR.

b Twenty-one strains were resistant to $\mathrm{EMB}$, ten to $\mathrm{SM}$ and two INH.

${ }^{c}$ Five strains were resistant to INH.

${ }^{d}$ Fifteen strains were resistant to INH, two to PZA 
Table 4: Mortality by phenotypic drug resistance profiles obtained at the Swiss National Centre for Mycobacteria and by concordance with local results.

\begin{tabular}{lccc}
\hline & $\begin{array}{c}\text { Concordant } \\
\text { results }\end{array}$ & $\begin{array}{c}\text { Discordant } \\
\text { results }\end{array}$ & Total \\
\hline Pan-susceptible & $17 / 302(5.6 \%)$ & $6 / 57(10.5 \%)$ & $23 / 359(6.4 \%)$ \\
Any resistance & $29 / 164(17.7 \%)$ & $15 / 50(30.0 \%)$ & $44 / 214(20.6 \%)$ \\
Mono-resistance & & & \\
INH & $5 / 8(62.5 \%)$ & $2 / 15(13.3 \%)$ & $7 / 23(30.4 \%)$ \\
RIF & $0 / 7(0 \%)$ & $2 / 7(28.6 \%)$ & $2 / 14(14.3 \%)$ \\
PZA & - & $1 / 2(50.0 \%)$ & $1 / 2(50.0 \%)$ \\
Poly-resistance & & & $24 / 146(14.4 \%)$ \\
MDR & $22 / 138(15.9 \%)$ & $2 / 8(25.0 \%)$ & $10 / 29(34.5 \%)$ \\
Pre-XDR/XDR & $2 / 11(18.2 \%)$ & $8 / 18(44.4 \%)$ & \\
& & & $67 / 573(11.7 \%)$ \\
\hline
\end{tabular}

Analysis based on 573 patients with complete data (see supplementary Figure S1). 
Table 5. Results from logistic regression models of the probability of death during tuberculosis treatment.

$\begin{array}{ccccc}\begin{array}{c}\text { No. of } \\ \text { patients }\end{array} & \begin{array}{c}\text { No. of } \\ \text { deaths }(\%)\end{array} & \begin{array}{c}\text { Model 1 } \\ \text { aOR }(95 \% \mathrm{Cl})\end{array} & \begin{array}{c}\text { Model 2 } \\ \text { aOR }(95 \% \mathrm{Cl})\end{array} & \begin{array}{c}\text { Model 3 } \\ \text { aOR }(95 \% \mathrm{Cl})\end{array}\end{array}$

\title{
Concordance / discordance of DST results
}

Concordance

Discordance potentially

leading to under treatment

Discordance potentially

leading to over treatment

Other discordance

$\begin{array}{ccc}466 & 46(9.9) & 1 \\ 22 & 9(40.9) & 7.33(2.70-19.95) \\ 61 & 6(9.8) & 0.81(0.31-2.11) \\ 24 & 6(25.0) & 4.92(1.69-14.33)\end{array}$

\section{Drug resistance ${ }^{a}$}

Pan-susceptible

Mono-resistance

359

$23(6.4)$

$39 \quad 10(25.6)$

1

MDR

146

$24(16.4)$

$6.05(2.36-15.56)$

Pre-XDR/XDR

29

10 (34.5)

\section{Treatment adequacy by \\ drug resistance}

Pan-susceptible, compatible

with WHO guidelines

$336 \quad 20(6.0)$

1

Pan-susceptible, over

treatment

$23 \quad 3(13.0)$

$3.31(0.82-13.45)$

Any resistance, compatible

with WHO guidelines

$200 \quad 36(18.0)$

$4.66(2.16-9.14)$

$14 \quad 8(57.1)$

$19.32(5.59-66.73)$

treatment

\section{Sex}

Female

$219 \quad 20(9.1)$

354

47 (13.3)

$1.47(0.81-2.67)$

1

Male

573

$573 \quad 67(11.7)$

$1.04(1.01-1.06)$

$1.42(0.78-2.60)$

$1.46(0.80-2.70)$

Age (per 1 year increase)

$1.04(1.01-1.06)$

$1.04(1.01-1.06)$

\section{Sputum microscopy}

Negative

111

$10(9.0)$

1

Positive

$462 \quad 57(12.3)$

$1.14(0.51-2.56)$

1

1

$1.03(0.45-2.37)$

$0.90(0.40-2.07)$

\section{HIV status}

Negative

Positive

337

$43(12.8)$

1

$236 \quad 24(10.2) \quad 0.90(0.50-1.61) \quad 1.19(0.65-2.20)$

$236 \quad 24(10.2) \quad 0.90(0.50-1.61) \quad 1.19(0.65-2.20)$

1

1

$1.19(0.65-2.20)$

\begin{abstract}
Models based on 573 patients with complete data for all variables shown (see supplementary Figure S1).
Model 1 was adjusted for concordance / discordance of DST results, sex, age, sputum microscopy and HIV status; model 2 was adjusted for drug resistance, sex, age, sputum microscopy and HIV status; model 3 was adjusted for treatment adequacy, sex, age, sputum microscopy and HIV status.
\end{abstract}

Abbreviations: DST, drug susceptibility testing; MDR, multidrug resistant; XDR, extensively drug-resistant

${ }^{\text {a }}$ Results from the Swiss National Reference Center for Mycobacteria 
Figure 1: Mortality according to drug resistance, to concordance or discordance of drug susceptibility testing (DST) results and to treatment adequacy. Error bars are standard errors. All $P$ values $<0.001$ for difference in mortality across categories. Analysis based on 573 patients with complete data.

Supplemental Tables and Figures 


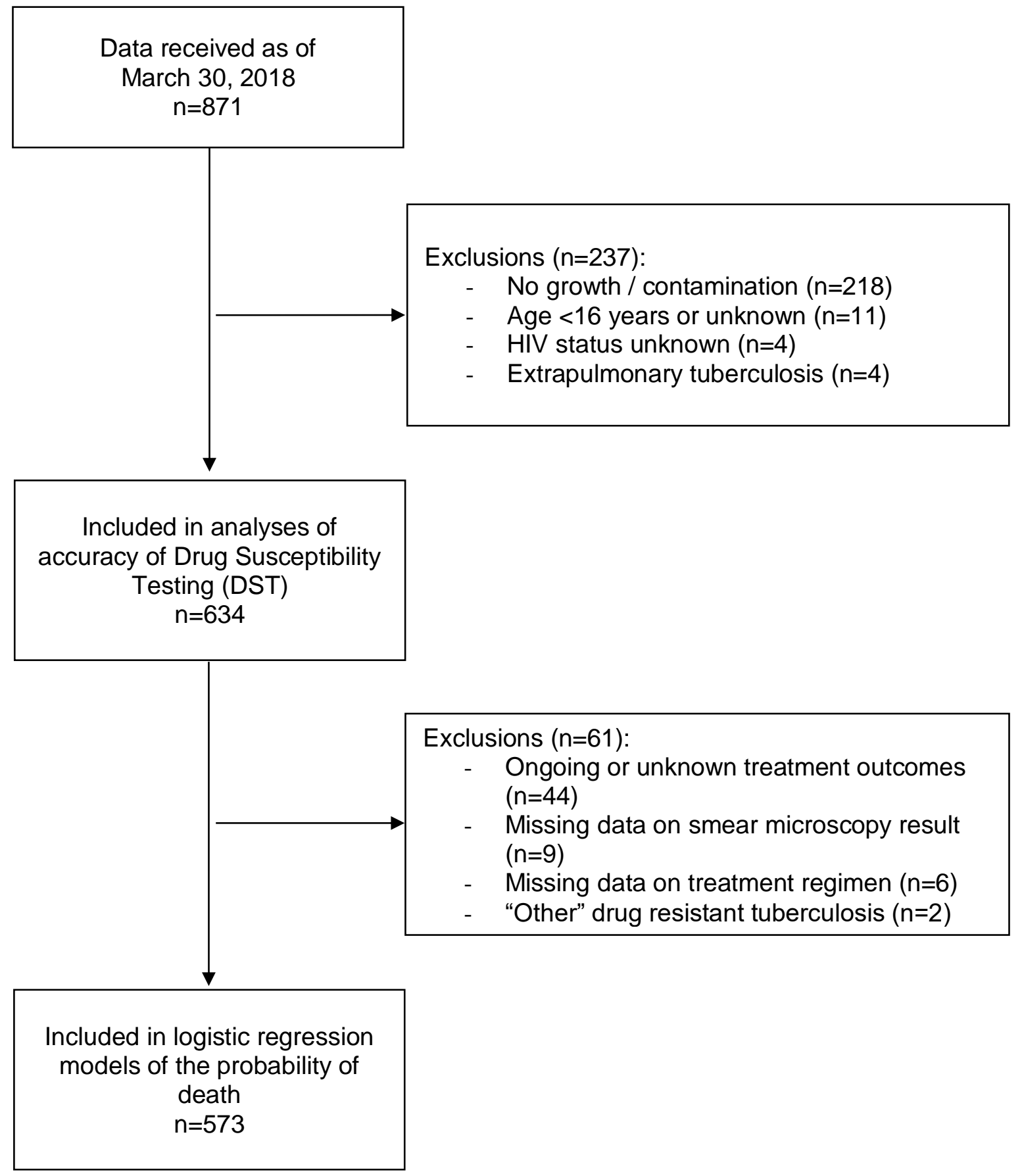


Table S1: Characteristics of participating study sites and settings.

\begin{tabular}{|c|c|c|c|c|c|c|c|}
\hline & Côte d'Ivoire & Nigeria & $\begin{array}{c}\text { Democratic } \\
\text { Republic of the } \\
\text { Congo }\end{array}$ & Kenya & South Africa & Peru & Thailand \\
\hline \multicolumn{8}{|l|}{ Study sites } \\
\hline Location & Abidjan & Zaria & Kinshasa & Eldoret & $\begin{array}{l}\text { Khayelitsha, Cape } \\
\text { Town }\end{array}$ & Lima & Bangkok \\
\hline Setting & Urban & Rural & Urban & Rural & Urban & Urban & Urban \\
\hline Recruitment & $\begin{array}{l}\text { Centre de Prise en } \\
\text { charge de } \\
\text { Recherche et de } \\
\text { Formation } \\
\text { (CePReF), and } \\
\text { affiliated TB clinics }\end{array}$ & $\begin{array}{l}\text { National TB and } \\
\text { Leprosy Training } \\
\text { Center (NTBLTC), } \\
\text { and affiliated TB } \\
\text { clinics }\end{array}$ & $\begin{array}{l}\text { Kalembelembe } \\
\text { Hospital, ART } \\
\text { program, and } \\
\text { affiliated TB clinics }\end{array}$ & $\begin{array}{l}\text { Academic Model } \\
\text { Providing Access to } \\
\text { Healthcare } \\
\text { (AMPATH), and } \\
\text { affiliated TB clinics }\end{array}$ & $\begin{array}{l}\text { Khayelitsha ART } \\
\text { Program, } \\
\text { Khayelitsha } \\
\text { township, and } \\
\text { affiliated TB clinics }\end{array}$ & $\begin{array}{l}\text { Instituto de Medicina } \\
\text { Tropical Alexander von } \\
\text { Humboldt; Universidad } \\
\text { Peruana Cayetano } \\
\text { Heredia, and affiliated } \\
\text { TB clinics }\end{array}$ & $\begin{array}{l}\text { HIV Netherlands Australia } \\
\text { Thailand Research } \\
\text { Collaboration (HIV-NAT), } \\
\text { King Chulalongkorn } \\
\text { Memorial Hospital, and } \\
\text { affiliated TB clinics }\end{array}$ \\
\hline Laboratory facilities & $\begin{array}{l}\text { Centre de } \\
\text { Diagnostic et de } \\
\text { Recherche sur le } \\
\text { Sida (CeDReS) }\end{array}$ & $\begin{array}{l}\text { NTBLTC National } \\
\text { TB reference } \\
\text { laboratory }\end{array}$ & $\begin{array}{l}\text { National TB } \\
\text { Laboratory }\end{array}$ & $\begin{array}{l}\text { Mycobacteriology } \\
\text { Laboratory at } \\
\text { AMPATH }\end{array}$ & $\begin{array}{l}\text { National Health } \\
\text { Laboratory Service, } \\
\text { and Molecular } \\
\text { Biology Laboratory, } \\
\text { Stellenbosch } \\
\text { University }\end{array}$ & $\begin{array}{l}\text { National TB Lab and } \\
\text { Instituto de Medicina } \\
\text { Tropical A. von } \\
\text { Humboldt TB Research } \\
\text { Laboratory }\end{array}$ & $\begin{array}{l}\text { HIV-NAT Research } \\
\text { Laboratory }\end{array}$ \\
\hline $\begin{array}{l}\text { Drug susceptibility } \\
\text { testing methods }\end{array}$ & $\begin{array}{l}\text { Löwenstein-Jensen } \\
\text { proportion culture }\end{array}$ & $\begin{array}{l}\text { Xpert MTB/RIF, } \\
\text { MGIT liquid culture, } \\
\text { line probe assays }\end{array}$ & $\begin{array}{l}\text { Xpert MTB/RIF, } \\
\text { Löwenstein-Jensen } \\
\text { proportion culture }\end{array}$ & Xpert MTB/RIF & $\begin{array}{l}\text { Xpert MTB/RIF, } \\
\text { MGIT liquid culture, } \\
\text { line probe assays }\end{array}$ & $\begin{array}{l}\text { Löwenstein-Jensen } \\
\text { proportion method, } \\
\text { MGIT liquid culture }\end{array}$ & MGIT liquid culture \\
\hline \multicolumn{8}{|l|}{ Country TB statistics } \\
\hline \multicolumn{8}{|l|}{ Incidence (including HIV) } \\
\hline Number (thousands) & 36 & 407 & 254 & 169 & 438 & 37 & 119 \\
\hline Rate $^{\mathrm{a}}$ & 153 & 219 & 323 & 348 & 781 & 117 & 172 \\
\hline \multicolumn{8}{|l|}{ Incidence MDR/RR-TB } \\
\hline Number (thousands) & 2.1 & 20 & 7.6 & 3 & 19 & 3.5 & 4.7 \\
\hline Rate $^{a}$ & 8.9 & 11 & 9.7 & 6.2 & 34 & 11 & 6.8 \\
\hline \multicolumn{8}{|l|}{$\begin{array}{l}\text { Mortality (HIV-negative } \\
\text { and HIV-positive people) }\end{array}$} \\
\hline Rate $^{a}$ & 12 & 21 & 11 & 50 & 181 & 1.5 & 5.7 \\
\hline
\end{tabular}

MGIT, Mycobacteria Growth Indicator Tube; MDR, multidrug resistant; RR rifampicin resistant; TB, tuberculosis;

a per 100,000 population (from Global Tuberculosis Report 2017. Geneva: World Health Organization, 2017) 
Table S2: Classification of treatment regimens by drug resistance profile.

\begin{tabular}{|c|c|c|c|c|c|c|c|}
\hline \multirow{2}{*}{$\begin{array}{l}\text { Drug resistances } \\
\text { according to Swiss } \\
\text { National Center for } \\
\text { Mycobacteria }\end{array}$} & \multirow{2}{*}{$\begin{array}{l}\text { Total } \\
\\
\text { No. } \\
\end{array}$} & \multicolumn{2}{|c|}{ Compatible with WHO guidelines } & \multicolumn{2}{|c|}{ Over-treatment } & \multicolumn{2}{|c|}{ Under-treatment } \\
\hline & & No. & Treatment regimen & No. & Treatment regimen & No. & Treatment regimen \\
\hline Pan-susceptible & 394 & 369 & 2 INH-RIF-PZA-EMB / 4 INH-RIF & $\begin{array}{l}1 \\
1 \\
2 \\
2 \\
1 \\
3 \\
1 \\
14\end{array}$ & $\begin{array}{l}2 \text { INH-PZA-EMB-OFX } \\
2 \text { INH-PZA-EMB-SM-OFX } \\
2 \text { INH-RIF-PZA-EMB-SM / } 1 \text { INH-RIF-PZA- } \\
\text { EMB / } 5 \text { INH-RIF-EMB } \\
2 \text { INH-RIF-PZA-EMB / } 4 \text { INH -RIF } \\
6 \text { PZA-EMB-KM / CM-LFX-PTO-CS / } 14 \\
\text { PZA-EMB-LFX-PTO-CS } \\
8 \text { PZA-KM-PTO-CS-LFX / } 12 \text { PZA-PTO-CS- } \\
\text { LFX } \\
\text { PZA-KM-LFX-PTO-CS } \\
\text { PZA-EMB-KM-ETO-MOX-TRD }\end{array}$ & & \\
\hline Mono-resistance & 45 & & & & & & \\
\hline INH mono-resistance & 29 & $\begin{array}{l}27 \\
1 \\
1\end{array}$ & $\begin{array}{l}2 \text { INH-RIF-PZA-EMB / } 4 \text { INH-RIF } \\
\text { PZA-EMB-KM-LFX-ETO-CS } \\
\text { RIF-PZA-EMB-LFX }\end{array}$ & & & & \\
\hline RIF mono-resistance & 14 & $\begin{array}{l}7 \\
3 \\
2 \\
1 \\
1\end{array}$ & $\begin{array}{l}\text { PZA-EMB-KM-ETO-MOX-TRD } \\
\text { PZA-KM-LFX-PTO-CS } \\
\text { PZA-AM-LFX-PTO-CS } \\
8 \text { PZA-KM-PTO-CS-LFX / } 12 \text { PZA-PTO-CS- } \\
\text { LFX } \\
4 \text { INH-PZA-EMB-KM-MOX-PTO-CFZ / } 5 \text { EMB- } \\
\text { PZA-MOX-CFZ }\end{array}$ & & & & \\
\hline PZA mono-resistance & 2 & 2 & 2 INH-RIF-PZA-EMB / 4 INH-RIF & & & & \\
\hline $\begin{array}{l}\text { MDR } \\
\text { INH+RIF }\end{array}$ & $\begin{array}{l}163 \\
85\end{array}$ & $\begin{array}{l}2 \\
31 \\
1 \\
4 \\
2 \\
2 \\
1 \\
1 \\
1 \\
1 \\
13\end{array}$ & $\begin{array}{l}2 \text { INH-RIF-PZA-EMB-SM / } 1 \text { INH-RIF-PZA- } \\
\text { EMB / } 5 \text { INH-RIF-EMB } \\
4 \text { INH-PZA-EMB-KM-MOX-PTO-CFZ / } 5 \text { EMB- } \\
\text { PZA-MOX-CFZ } \\
6 \text { PZA-EMB-KM / CM-LFX-PTO-CS / } 14 \text { PZA- } \\
\text { EMB-LFX-PTO-CS } \\
8 \text { PZA-KM-PTO-CS-LFX / } 12 \text { PZA-PTO-CS- } \\
\text { LFX } \\
\text { PZA-AM-LFX-PTO-CS } \\
\text { PZA-EMB-KM-CS-ETO-CFX-PAS } \\
\text { PZA-EMB-KM-ETO-CFX-CS } \\
\text { PZA-EMB-KM-ETO-LFX-PAS } \\
\text { PZA-EMB-KM-LFX-CS } \\
\text { PZA-EMB-KM-LFX-ETO-CS } \\
\text { PZA-KM-LFX-PTO-CS }\end{array}$ & & & 10 & $\begin{array}{l}2 \text { INH-RIF-PZA- } \\
\text { EMB / } 4 \text { INH-RIF }\end{array}$ \\
\hline
\end{tabular}




\begin{tabular}{|c|c|c|c|c|c|}
\hline & & $\begin{array}{l}1 \\
10 \\
1\end{array}$ & $\begin{array}{l}\text { RIF-PZA-EMB-LFX } \\
\text { PZA-EMB-KM-ETO-MOX-TRD } \\
\text { PZA-KM-LFX-ETO-CS-PAS }\end{array}$ & & \\
\hline \multirow[t]{4}{*}{$\mathrm{INH}+\mathrm{RIF}+\mathrm{EMB}$} & 11 & 5 & $\begin{array}{l}4 \text { INH-PZA-EMB-KM-MOX-PTO-CFZ / } 5 \text { EMB- } \\
\text { PZA-MOX-CFZ }\end{array}$ & 1 & $\begin{array}{l}2 \text { INH-RIF-PZA- } \\
\text { EMB / } 4 \text { INH-RIF }\end{array}$ \\
\hline & & 1 & $\begin{array}{l}8 \text { PZA-KM-PTO-CS-LFX / } 12 \text { PZA-PTO-CS- } \\
\text { LFX }\end{array}$ & & \\
\hline & & 1 & PZA-KM-LFX-PTO-CS & & \\
\hline & & 3 & PZA-EMB-KM-ETO-MOX-TRD & & \\
\hline \multirow[t]{12}{*}{$\mathrm{INH}+\mathrm{RIF}+\mathrm{PZA}$} & 47 & 1 & $\begin{array}{l}2 \text { INH-RIF-PZA-EMB-SM / } 1 \text { INH-RIF-PZA- } \\
\text { EMB / } 5 \text { INH-RIF-EMB }\end{array}$ & 2 & $\begin{array}{l}2 \text { INH-RIF-PZA- } \\
\text { EMB / } 4 \text { INH-RIF }\end{array}$ \\
\hline & & 17 & $\begin{array}{l}4 \text { INH-PZA-EMB-KM-MOX-PTO-CFZ / } 5 \text { EMB- } \\
\text { PZA-MOX-CFZ }\end{array}$ & & \\
\hline & & 1 & $\begin{array}{l}8 \text { PZA-KM-PTO-CS-LFX / } 12 \text { PZA-PTO-CS- } \\
\text { LFX }\end{array}$ & & \\
\hline & & 1 & PZA-AM-LFX-PTO-C & & \\
\hline & & 1 & EMB-KM-LFX-ETO-CS & & \\
\hline & & 3 & PZA-EMB-KM-LFX-ETO-CS & & \\
\hline & & 1 & PZA-EMB-LFX-AM-ETO-CS & & \\
\hline & & 1 & INH-PZA-EMB-KM-LFX & & \\
\hline & & 1 & $\begin{array}{l}\text { INH-PZA-EMB-CFZ-ETO-KM-LZD-MOX-PAS- } \\
\text { TRD-BDQ-DLM }\end{array}$ & & \\
\hline & & 4 & PZA-KM-LFX-PTO-CS & & \\
\hline & & 12 & PZA-EMB-KM-ETO-MOX-TRD & & \\
\hline & & 1 & PZA-KM-LFX-ETO-CS-PAS & & \\
\hline \multirow[t]{7}{*}{$\mathrm{INH}+\mathrm{RIF}+\mathrm{EMB}+\mathrm{PZA}$} & 20 & 2 & $\begin{array}{l}4 \text { INH-PZA-EMB-KM-MOX-PTO-CFZ / } 5 \text { EMB- } \\
\text { PZA-MOX-CFZ }\end{array}$ & 1 & $\begin{array}{l}2 \text { INH-RIF-PZA- } \\
\text { EMB / } 4 \text { INH-RIF }\end{array}$ \\
\hline & & 2 & $\begin{array}{l}6 \text { PZA-EMB-KM / CM-LFX-PTO-CS / } 14 \text { PZA- } \\
\text { EMB-LFX-PTO-CS }\end{array}$ & & \\
\hline & & 1 & $\begin{array}{l}8 \text { PZA-KM-PTO-CS-LFX / } 12 \text { PZA-PTO-CS- } \\
\text { LFX }\end{array}$ & & \\
\hline & & 1 & PZA-AM-LFX-PTO-CS & & \\
\hline & & 3 & PZA-EMB-KM-LFX-ETO-CS & & \\
\hline & & 3 & PZA-KM-LFX-PTO-CS & & \\
\hline & & 6 & PZA-EMB-KM-ETO-MOX-TRD & & \\
\hline Pre-XDR & 24 & & & & \\
\hline $\mathrm{INH}+\mathrm{RIF}+\mathrm{AMK}$ & 1 & 1 & $\begin{array}{l}4 \text { INH-PZA-EMB-KM-MOX-PTO-CFZ / } 5 \text { EMB- } \\
\text { PZA-MOX-CFZ }\end{array}$ & & \\
\hline \multirow[t]{2}{*}{$\mathrm{INH}+\mathrm{RIF}+\mathrm{AMK}+\mathrm{PZA}$} & 4 & 1 & $\begin{array}{l}4 \text { INH-PZA-EMB-KM-MOX-PTO-CFZ / } 5 \text { EMB- } \\
\text { PZA-MOX-CFZ }\end{array}$ & & \\
\hline & & $\begin{array}{l}1 \\
2\end{array}$ & $\begin{array}{l}\text { PZA-EMB-KM-CS-ETO-CFX-PAS } \\
\text { Z-CFZ-ETO-KM-LZD-MOX-PAS }\end{array}$ & & \\
\hline \multirow[t]{2}{*}{$\mathrm{INH}+\mathrm{RIF}+\mathrm{AMK}+\mathrm{PZA}+\mathrm{EMB}$} & 4 & 2 & Z-CFZ-ETO-KM-LZD-MOX-PAS & 1 & $\begin{array}{l}2 \text { INH-RIF-PZA- } \\
\text { EMB / } 4 \text { INH-RIF }\end{array}$ \\
\hline & & 1 & $\begin{array}{l}4 \text { INH-PZA-EMB-KM-MOX-PTO-CFZ / } 5 \text { EMB- } \\
\text { PZA-MOX-CFZ }\end{array}$ & & \\
\hline $\mathrm{INH}+\mathrm{RIF}+\mathrm{MOX}$ & 2 & 1 & 4 INH-PZA-EMB-KM-MOX-PTO-CFZ / 5 EMB- & & \\
\hline
\end{tabular}


INH+RIF +MOX+EMB 1 1 4 INH-PZA-EMB-KM-MOX-PTO-CFZ / 5 EMB-

INH+RIF+MOX+PZA $4 \quad 3 \quad 4$ INH-PZA-EMB-KM-MOX-PTO-CFZ / 5 EMB-

PZA-MOX-CFZ

INH-PZA-EMB-CFZ-ETO-KM-LZD-MOX-PAS-

TRD-BDQ-DLM

$\mathrm{INH}+\mathrm{RIF}+\mathrm{MOX}+\mathrm{EMB}+\mathrm{PZA}$

24 INH-PZA-EMB-KM-MOX-PTO-CFZ / 5 EMB-

PZA-MOX-CFZ

INH-PZA-EMB-CFZ-ETO-KM-LZD-MOX-PAS-

TRD-BDQ-DLM

PZA-KM-LFX-PTO-CS

6 PZA-EMB-KM-OFX-PTO-CS / 18 PZA-EMB-

OFX-PTO-CS

XDR

$\mathrm{INH}+\mathrm{RIF}+\mathrm{AMK}+\mathrm{MOX}+\mathrm{EMB}$

2 INH-PZA-EMB-CFZ-ETO-KM-LZD-MOX-PAS-

TRD-BDQ-DLM

4 INH-PZA-EMB-KM-MOX-PTO-CFZ / 5 EMB-

PZA-MOX-CFZ

INH+RIF +AMK+MOX+PZA 241 4 INH-PZA-EMB-KM-MOX-PTO-CFZ / 5 EMB-

PZA-MOX-CFZ

12 INH-RIF-PZA-

PZA-KM-LFX-PTO-CS

EMB / 4 INH-RIF

$\mathrm{INH}+\mathrm{RIF}+\mathrm{AMK}+\mathrm{MOX}$

Other

$\mathrm{INH}+\mathrm{MOX}$

$\mathrm{NH}+\mathrm{PZA}$

PZA-EMB-KM-ETO-MOX-TRD

2 INH-RIF-PZA-EMB / 4 INH-RIF

The treatment regimen was missing in six patients.

INH, isioniazid; RIF, rifampicin; PZA, pyrazinamide; EMB, ethambutol; SM, streptomycin; KM, kanamycin; AM, amikacin; CM, capreomycin; LFX, levofloxacin; OFX, Ofloxacin; MOX,

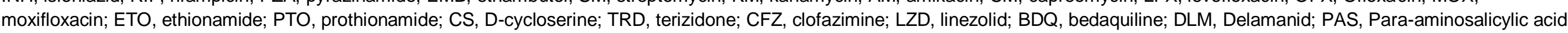


Table S3: Patient characteristics of included and excluded TB patients.

\begin{tabular}{|c|c|c|}
\hline & $\begin{array}{l}\text { Excluded patients } \\
(\mathrm{n}=237)\end{array}$ & $\begin{array}{l}\text { Included patients } \\
(n=634)\end{array}$ \\
\hline Age (years) & $33.3(26.8-42.0)$ & $33.2(26.9-42.5)$ \\
\hline No. of observations (\%) & $220(92.8)$ & \\
\hline \multicolumn{3}{|l|}{ Sex } \\
\hline Male & $135(57.0)$ & $395(62.3)$ \\
\hline Female & $102(43.0)$ & $239(37.7)$ \\
\hline \multicolumn{3}{|l|}{ HIV } \\
\hline Negative & $125(52.7)$ & $362(57.1)$ \\
\hline Positive & $108(45.6)$ & 272 \\
\hline Unknown & $4(1.7)$ & - \\
\hline \multicolumn{3}{|l|}{ Site of TB disease } \\
\hline Pulmonary & $230(97.1)$ & $609(96.1)$ \\
\hline Extrapulmonary & $4(1.7)$ & - \\
\hline Pulmonary and extrapulmonary & $1(0.4)$ & $25(3.9)$ \\
\hline Unknown & $2(0.8)$ & - \\
\hline CD4 count at baseline (cells/ $\mu \mathrm{l})$ & $129(88-185)$ & $192(77.5-369)$ \\
\hline No. of observations (\%) & $96(40.5)$ & $200(73.5)$ \\
\hline \multicolumn{3}{|l|}{ Type of TB patient } \\
\hline New patient & $111(46.8)$ & $411(64.8)$ \\
\hline Recurrent TB & $52(21.9)$ & $120(18.9)$ \\
\hline Treatment after failure & $42(17.8)$ & $70(11.0)$ \\
\hline Treatment after default & $29(12.2)$ & $27(4.3)$ \\
\hline Unknown & $3(1.3)$ & $6(0.9)$ \\
\hline \multicolumn{3}{|l|}{ Sputum smear microscopy } \\
\hline Negative & $26(11.0)$ & $113(17.8)$ \\
\hline Positive & $202(85.2)$ & $512(80.8)$ \\
\hline Unknown & $9(3.8)$ & $9(1.4)$ \\
\hline \multicolumn{3}{|l|}{ TB treatment outcome } \\
\hline Success & $126(53.2)$ & $411(64.8)$ \\
\hline Cure & $71(30.0)$ & $298(47.0)$ \\
\hline Treatment completed & 55 (23.2) & $113(17.8)$ \\
\hline Treatment failure & $2(0.8)$ & $22(3.5)$ \\
\hline Death & $7(3.0)$ & $69(10.9)$ \\
\hline Lost to follow-up & $11(4.6)$ & $59(9.3)$ \\
\hline Transfer & $11(4.6)$ & $29(4.6)$ \\
\hline Ongoing treatment & $44(18.6)$ & $4(0.6)$ \\
\hline Unknown & $36(15.2)$ & $40(6.3)$ \\
\hline
\end{tabular}

Numbers (\%) or median (interquartile range) are shown. 
Table S4: Patient characteristics by HIV status at diagnosis of tuberculosis.

\begin{tabular}{|c|c|c|c|c|}
\hline & $\begin{array}{l}\text { All Patients } \\
(n=634)\end{array}$ & $\begin{array}{l}\text { HIV-negative } \\
(n=362)\end{array}$ & $\begin{array}{l}\text { HIV-positive } \\
(\mathrm{n}=272)\end{array}$ & $\mathrm{p}$-value \\
\hline Age (years) & $33.2(26.9-42.5)$ & $31.7(25.1-43.3)$ & $34.7(29.1-42.0)$ & 0.49 \\
\hline \multicolumn{5}{|l|}{ Sex } \\
\hline Male & $395(62.3)$ & $249(69.8)$ & $146(53.7)$ & $<0.001$ \\
\hline Female & $239(37.7)$ & $113(31.2)$ & $126(46.3)$ & \\
\hline \multicolumn{5}{|l|}{ Site of TB disease } \\
\hline Pulmonary & $609(96.1)$ & $355(98.1)$ & $254(93.4)$ & 0.003 \\
\hline Pulmonary and extrapulmonary & $25(3.9)$ & $7(1.9)$ & $18(6.6)$ & \\
\hline CD4 count at baseline (cells $/ \mu$ l) & - & - & $192(77.5-369)$ & \\
\hline No. of observations (\%) & - & - & 200 (73.5) & \\
\hline Type of TB patient & & & & $<0.001$ \\
\hline New patient & $411(64.8)$ & $233(64.4)$ & $178(65.4)$ & \\
\hline Recurrent TB & $120(18.9)$ & $56(15.5)$ & $64(23.5)$ & \\
\hline Treatment after failure & $70(11.0)$ & $56(15.5)$ & $14(5.2)$ & \\
\hline Treatment after default & $27(4.3)$ & $15(4.1)$ & $12(4.4)$ & \\
\hline Unknown & $6(0.9)$ & $2(0.5)$ & $4(1.5)$ & \\
\hline Sputum smear microscopy & & & & $<0.001$ \\
\hline Negative & $113(17.8)$ & $46(12.7)$ & $67(24.6)$ & \\
\hline Positive & $512(80.8)$ & $312(86.2)$ & $200(73.5)$ & \\
\hline Unknown & $9(1.4)$ & $4(1.1)$ & $5(1.8)$ & \\
\hline TB drug resistance ${ }^{a}$ & & & & $<0.001$ \\
\hline Pan-susceptible & $394(62.1)$ & $200(55.2)$ & $194(71.3)$ & \\
\hline Any resistance & $240(37.9)$ & $162(44.8)$ & $78(28.7)$ & $<0.001$ \\
\hline Mono-resistant & $45(7.1)$ & $29(8.0)$ & $16(5.9)$ & \\
\hline MDR & $163(25.7)$ & $114(31.5)$ & $49(18.0)$ & \\
\hline Pre-XDR/XDR & $30(4.7)$ & $18(5.0)$ & $12(4.4)$ & \\
\hline Other & $2(0.3)$ & $1(0.3)$ & $1(0.4)$ & \\
\hline TB treatment outcome & & & & 0.012 \\
\hline Success & $411(64.8)$ & $238(65.7)$ & $173(63.6)$ & \\
\hline Cure & $298(47.0)$ & $169(46.7)$ & $129(47.4)$ & \\
\hline Treatment completed & $113(17.8)$ & $69(19.1)$ & $44(16.2)$ & \\
\hline Treatment failure & $22(3.5)$ & $10(2.8)$ & $12(4.4)$ & \\
\hline Death & 69 (10.9) & $43(11.9)$ & $26(9.6)$ & \\
\hline Lost to follow-up & $59(9.3)$ & $40(11.0)$ & $19(7.0)$ & \\
\hline Transfer & $29(4.6)$ & $17(4.7)$ & $12(4.4)$ & \\
\hline Ongoing treatment & $4(0.6)$ & $1(0.3)$ & $3(1.1)$ & \\
\hline Unknown & $40(6.3)$ & $13(3.6)$ & $27(9.9)$ & \\
\hline
\end{tabular}

\section{Country}

Côte d'Ivoire

Democratic Republic of the Congo

Kenya

Nigeria

Peru

South Africa

99 (15.6)

$62(9.8)$

$35(5.5)$

$56(8.8)$

$104(16.4)$

$187(29.5)$

$91(14.4)$

$57(15.7)$
$50(13.8)$
$15(4.1)$
$37(10.2)$
$64(17.7)$
$84(23.2)$
$55(15.2)$

Thailand

Analysis based on 634 patients (see supplementary Figure S1). Numbers (\%) or median (interquartile range) are shown.

MDR, multidrug resistant; TB, tuberculosis; XDR, extensively drug resistant

${ }^{\text {a }}$ Results from the Swiss National Reference Center for Mycobacteria 
Table S5. Results from univariable logistic regression models of the probability of death during tuberculosis treatment.

\begin{tabular}{|c|c|c|c|}
\hline & $\begin{array}{l}\text { No. of } \\
\text { patients }\end{array}$ & $\begin{array}{c}\text { No. of } \\
\text { deaths }(\%)\end{array}$ & $\begin{array}{l}\text { Odds ratio } \\
(95 \% \mathrm{Cl})\end{array}$ \\
\hline \multicolumn{4}{|l|}{$\begin{array}{l}\text { Concordance / discordance } \\
\text { of DST results }\end{array}$} \\
\hline Concordance & 466 & $46(9.9)$ & 1 \\
\hline $\begin{array}{l}\text { Discordance potentially } \\
\text { leading to under treatment }\end{array}$ & 22 & $9(40.9)$ & $6.32(2.56-15.59)$ \\
\hline $\begin{array}{l}\text { Discordance potentially } \\
\text { leading to over treatment }\end{array}$ & 61 & $6(9.8)$ & $1.00(0.41-2.44)$ \\
\hline Other discordance & 24 & $6(25.0)$ & $3.04(1.15-8.05)$ \\
\hline \multicolumn{4}{|l|}{ Drug resistance ${ }^{a}$} \\
\hline Pan-susceptible & 359 & $23(6.4)$ & 1 \\
\hline Mono-resistance & 39 & $10(25.6)$ & $5.03(2.19-11.60)$ \\
\hline MDR & 146 & $24(16.4)$ & $2.87(1.56-5.28)$ \\
\hline Pre-XDR/XDR & 29 & $10(34.5)$ & $7.69(3.21-18.44)$ \\
\hline \multicolumn{4}{|l|}{$\begin{array}{l}\text { Treatment adequacy by } \\
\text { drug resistance }\end{array}$} \\
\hline $\begin{array}{l}\text { Pan-susceptible, compatible } \\
\text { with WHO guidelines }\end{array}$ & 336 & $20(6.0)$ & 1 \\
\hline $\begin{array}{l}\text { Pan-susceptible, over } \\
\text { treatment }\end{array}$ & 23 & $3(13.0)$ & $2.37(0.65-8.65)$ \\
\hline $\begin{array}{l}\text { Any resistance, compatible } \\
\text { with WHO guidelines }\end{array}$ & 200 & $36(18.1)$ & $3.49(1.96-6.18)$ \\
\hline $\begin{array}{l}\text { Any resistance, under } \\
\text { treatment }\end{array}$ & 14 & $8(53.3)$ & $21.06(6.66-66.59)$ \\
\hline \multicolumn{4}{|l|}{ Sex } \\
\hline Female & 219 & $20(9.1)$ & 1 \\
\hline Male & 354 & $47(13.3)$ & $1.52(0.88-2.65)$ \\
\hline Age (per 1 year increase) & 573 & $67(11.7)$ & $1.03(1.01-1.05)$ \\
\hline \multicolumn{4}{|l|}{ Sputum microscopy } \\
\hline Negative & 111 & $10(9.0)$ & 1 \\
\hline Positive & 462 & $57(12.3)$ & $1.42(0.70-2.88)$ \\
\hline \multicolumn{4}{|l|}{ HIV status } \\
\hline Negative & 337 & $43(12.8)$ & 1 \\
\hline Positive & 236 & $24(10.2)$ & $0.77(0.46-1.31)$ \\
\hline
\end{tabular}

Models based on 573 patients with complete data for all variables shown (see supplementary Figure S1). Abbreviations: DST, drug susceptibility testing; MDR, multidrug resistant; XDR, extensively drug-resistant

${ }^{\text {a }}$ Results from the Swiss National Reference Center for Mycobacteria 